\title{
Covid-19: Aspectos da origem, fisiopatologia, imunologia e tratamento: uma revisão narrativa
}

\author{
Covid-19: Aspects of origin, pathophysiology, immunology and treatment: a narrative \\ review
}

Covid-19: Aspectos de origen, fisiopatología, inmunología y tratamiento: una revisión
narrative

Cayo Cesar da Silva ${ }^{1}$, Camilla Marcelle Ozorio de Carvalho ${ }^{1}$, Denis Costa de Lima ${ }^{1}$, Emmanuela Santos Costa ${ }^{1}$, Victória Maria Beltrão de Andrade ${ }^{1}$, Bruno Mendes Tenorio ${ }^{1}$, Diana Babini Lapa de Albuquerque Britto ${ }^{*}$, Fernanda Chagas Angelo Mendes Tenorio ${ }^{1}$.

\section{RESUMO}

Objetivo: descrever as principais informações descritas na literatura acerca das informações referentes a infecção pelo coronavírus e aspectos sobre o surgimento da doença, fisiopatologia, imunologia e tratamento. Revisão bibliográfica: A Covid-19, por meio do vírus SARS-CoV-2, apesar de ser de uma família viral conhecida até mesmo de outra pandemia no passado, possui mecanismos que precisam ser estudados para compreender com detalhes informações acerca da sua etiologia, mecanismos de infecção e tratamentos eficazes no combate da infecção. Análises microscópicas de amostras teciduais além do entendimento da imunologia aplicada à defesa viral podem ser a solução para o desenvolvimento de vacinas que consigam realizar uma proteção eficaz contra o vírus e suas mutações já conhecidas. O tratamento e as vacinas, em sua maioria, ainda se encontram em fase final de testes e sua distribuição para a população a partir da aprovação da eficácia, pode levar um bom tempo, e até lá, muitas pessoas poderão perder a vida. Considerações finais: Estudos voltados a fisiopatologia e principalmente, imunologia da SARS-CoV2 podem facilitar o desenvolvimento de terapêuticas mais eficazes e de vacinas contra a infecção do coronavírus, diminuindo o número de mortos e infectados por todo o mundo e ajudando o reestabelecimento da economia pós normalidade.

Palavras-chave: Covid-19, Imunologia, Fisiopatologia, Tratamento.

\begin{abstract}
Objective: describe the main information described in the literature about information related to infection by the coronavirus and aspects about the onset of the disease, pathophysiology, immunology and treatment. Literature review: Covid-19, using the SARS-CoV2 virus, despite being from a viral family known even from another pandemic in the past, has mechanisms that need to be studied to understand in detail information about its etiology, mechanisms infection and effective treatments to fight infection. Microscopic analysis of tissue samples in addition to understanding immunology applied to viral defense may be the solution for the development of vaccines that can provide effective protection against the virus and its already known mutations. The treatment and vaccines, for the most part, are still in the testing phase and their distribution to the population after the approval of efficacy, can take a long time, and until then, many people may lose their lives. Final considerations: Studies focused on pathophysiology and especially immunology of SARS-CoV2 can facilitate the development of more effective therapies and vaccines against coronavirus infection, reducing the number of deaths and infections worldwide and helping to reestablish the post-normal economy.
\end{abstract}

Key words: Covid-19, Immunology, Physiopathology, Treatment.

\section{RESUMEN}

Objetivo: describir la principal información descrita en la literatura sobre información relacionada con la infección por coronavirus y aspectos sobre el inicio de la enfermedad, fisiopatología, inmunología y tratamiento. Revisión bibliográfica: Covid-19, que usa el virus SARS-CoV2, apesar de ser de una familia viral conocida incluso de otra pandemia en el pasado, tiene mecanismos que deben estudiarse para comprender en detalle la información sobre su etiología, mecanismos infección y tratamientos efectivos para combatir la infección. El análisis microscópico de muestras de tejido, además de comprender la inmunología

1 Universidade Federal de Pernambuco (UFPE), Recife - PE. *E-mail: diana.babini@gmail.com 
aplicada a la defensa viral, puede ser la solución para el desarrollo de vacunas que puedan proporcionar una protección efectiva contra el virus y sus mutaciones ya conocidas. El tratamiento y las vacunas, en su mayor parte, todavía están en la fase de prueba y su distribución a la población después de la aprobación de la eficacia, puede llevar mucho tiempo y, hasta entonces, muchas personas pueden perder la vida. Consideraciones finales: Los estudios centrados en la fisiopatología y especialmente la inmunología del SARS-CoV2 pueden facilitar el desarrollo de terapias y vacunas más efectivas contra la infección por coronavirus, reduciendo el número de muertes e infecciones en todo el mundo y ayudando a restablecer la economía posnormal.

Palabras clave: Covid-19, Inmunología, Fisiopatología, Tratamiento.

\section{INTRODUÇÃO}

Conforme relato da literatura, coronavírus são RNA vírus causadores de infecções respiratórias, ocorrendo em uma gama de animais, podendo-se destacar as aves e os mamíferos (FEHR AR e PERLMAN S; 2015). Os coronavírus sazonais estão, na sua grande maioria, associados a síndromes gripais, sendo sete deles reconhecidos como patógenos em humanos. Nos últimos anos, dois deles foram responsáveis por epidemias muito virulentas de Síndrome respiratória aguda grave (SRAG). A Organização Mundial de Saúde (OMS) (2020) relata que, no ano de 2003, em Hong Kong (China), emergiu à epidemia da SARS, com letalidade de aproximadamente 10\%. Já em 2012, na Arábia Saudita, emergiu a Síndrome respiratório do Oriente Médio (MERS) com letalidade de 30\%.

Ambos fazem parte da lista de doenças prioritárias no âmbito da pesquisa e desenvolvimento no contexto emergencial (WHO, 2020). Após 16 anos, surgiu em Wuhan, na China, o surto do SARS-CoV-2 (Síndrome Respiratória Aguda Grave de coronavírus 2) e, assim como seu antecessor, apresentou rápida disseminação mundial. Tal cenário levou à declaração de Emergência em Saúde Pública de Interesse Internacional da OMS em 30 de janeiro de 2020. A partir de 11 de fevereiro de 2020, OMS passou a chamar a infecção pelo 2019nCov como Covid-19 (Coronavírus Disease-2019) e, a partir de 11 de março de 2020, também foi declarado como sendo uma pandemia. Em 25 de janeiro de 2021, a Universidade Johns Hopkins em Baltimore, EUA, estimou 99.245.800 casos do novo coronavírus no mundo com um total de 2.130.657 mortes (BBC, 2020).

É importante salientar que no espectro da infecção do SARS-CoV-2 pode ser apresentado de forma muito ampla, sendo desde uma infecção assintomática, como uma doença leve do trato respiratório superior e pneumonia viral grave com insuficiência respiratória, podendo evoluir para óbito (GORBALENYA AE, et al., 2020). Cerca de $80 \%$ dos pacientes infectados com o coronavírus podem ser assintomáticos, ou seja, não apresentam nenhum sintoma, $20 \%$ dos casos podem necessitar de atendimento hospitalar devido à dificuldade respiratória estabelecida e aproximadamente $5 \%$ dos infectados podem requerer tratamento para insuficiência respiratória, em conformidade com estudos da OMS (WHO, 2020).

A covid-19 é de fácil transmissão e de forma geral, tende a acometer de forma mais grave pacientes portadores de debilidades crônicas. Indivíduos com doentes pulmonares, doenças renais crônicas, pacientes com diabetes, hipertensão, cardiopatias, usuários de corticoides ou drogas imunossupressoras, tabagistas e idosos, correspondem à parte da população mais susceptível ao desenvolvimento da doença pneumonia (WU Z e MCGOOGAN JM, 2020). Febre, tosse seca e falta de ar são considerados os sintomas clássicos da infecção pelo SARS-CoV-2, onde normalmente aparece entre o $2^{\circ}$ e $014^{\circ}$ dia de infecção (KOWALSKI LP, et al., 2020).

O Ministério da Saúde (2020) relata que indivíduos infectados por coronavírus também podem apresentar outros sintomas, como por exemplo: produção de escarro, obstrução nasal, congestão conjuntival, dificuldade na deglutição, dor de garganta, coriza, saturação de $\mathrm{O} 2<95 \%$, sinais de cianose, batimentos da asa de nariz e, por fim, dispneia. Outros sinais e sintomas inespecíficos como: fadiga, mialgia/artralgia, cefaleia, calafrios, linfonodomegalia, diarreia, náusea, vômito, desidratação e inapetência também podem estar presentes.

Para Lu W, et al. (2020), o vírus se liga às células alveolares por meio de uma proteína conhecida como enzima conversora de angiotensina 2 (ECA2), o que pode causar tanto uma lesão pulmonar aguda como um edema pulmonar, resultando, assim, em hipoxemia grave e insuficiência respiratória, sendo responsável pela necessidade de tratamento para insuficiência respiratória. 
Na mesma pesquisa, a análise histológica demonstrou que o dano alveolar resultou em um infiltrado de células inflamatórias mistas nos espaços intersticiais e em torno de bronquíolos, resíduos celulares e inserção da fibrina nos espaços alveolares (LU W, et al., 2020). O estudo histológico das estruturas pulmonares é fundamental para obtenção e atualização dos conhecimentos neste momento em que há uma necessidade muito grande para descobrir métodos cada vez mais eficazes e que consigam reduzir ou até mesmo zerar o número de mortes acometidas pela doença.

Por meio da visualização microscópica dessas estruturas, é possível compreender melhor o mecanismo fisiopatológico da doença, a gravidade das alterações e danos que estão ocorrendo com maior frequência e associar a isso novas pesquisas para otimizar a prevenção, o diagnóstico e o tratamento (LU W, et al., 2020). Diante do exposto, o estudo objetiva descrever as principais informações descritas na literatura acerca das informações referentes a infecção pelo coronavírus e aspectos sobre o surgimento da doença, fisiopatologia, imunologia e tratamento.

\section{REVISÃO BIBLIOGRÁFICA}

\section{Início da doença}

Os coronavírus (CoV) faz parte de um grupo conhecido desde meados da década de 1960 (PIMENTEL RMM, et al., 2020). Recebem essa nomenclatura devido às espículas na sua superfície, que lembram uma coroa (do latim corona). Pimentel RMM, et al. (2020) ainda afirmam que os relatos científicos tinham conhecimento de seis espécies de coronavírus que causam doenças humanas. Quatro deles causam sintomas comuns de resfriado. Entretanto os outros dois, de origem zoonótica, mais graves, relacionados com o surgimento de infecções com alto impacto na saúde pública devido a sua letalidade, são eles: coronavírus da síndrome respiratória aguda grave (SARS-CoV), o agente responsável pelos surtos em 2002 e 2003 na província de Guangdong, China, e o outro coronavírus da síndrome respiratória do Oriente Médio (MERSCoV) responsável pelos graves surtos de doenças respiratórias em 2012 no Oriente Médio.

A alta letalidade é uma das principais características que diferenciam os surtos de coronavírus SARS e MERS das outras quatro espécies conhecidas por causarem sintomas comuns de resfriados. O SARS-CoV2 é o sétimo coronavírus, que causa a doença Covid-19. Segundo Li YC, et al. (2020) os coronavírus (CoVs), que são grandes vírus de RNA de sentido positivo não segmentados e envelopados, normalmente estão relacionados com doenças entéricas e respiratórias em animais e humanos. Li YC, et al. (2020) também relatam que a análise genômica apresenta que o SARS-CoV2 está no mesmo lado que o MERS-CoV e o SARS-CoV e compartilha uma sequência altamente homológica com o SARS-CoV.

Segundo Garcia LP e Duarte E (2020), a Covid-19 foi detectada em dezembro de 2019, em Wuhan, na China. Com a expansão no número de casos, óbitos e países afetados, a OMS atestou que o evento constituía uma Emergência de Saúde Pública de Importância Internacional (ESPII), em 30 de janeiro de 2020. A elevada infectividade do SARS-CoV2, na ausência de imunidade prévia na população humana, bem como de vacina contra este vírus, faz com que o acréscimo na apuração de casos seja exponencial.

É relevante também que o público e os profissionais de saúde estejam cientes da resistência do vírus, pautada como uma característica informativa de perspectiva em saúde pública. Triggle CR, et al. (2020) afirmam que quando na forma de aerossol ao deixar um hospedeiro humano, o SARS-CoV2 tem uma meiavida de 1,1 a 1,2 h, com um intervalo que apresenta conformidade ao ser analisado com o SARS-CoV1. Todavia, é importante ressaltar que a meia-vida do SARS-CoV2 em plástico e metal é muito mais longa, com uma meia-vida de $5,8 \mathrm{~h}$ para aço inoxidável (e menos para cobre e papelão), mas uma meia-vida de $6,8 \mathrm{~h}$ em plástico (TRIGGLE CR et al., 2020).

\section{Fisiopatologia da infecção}

Diante do cenário promovido pelo novo coronavírus, diversas repercussões estão sendo levantadas para analisar os efeitos histopatológicos desencadeados dentro dessa perspectiva. Conferida como a nova pneumonia, a infecção pelo coronavírus SARS-CoV2 é altamente contagiosa e prejudicial. Segundo Yao XH, et al. (2020), os sinais clínicos e sintomas respiratórios são caracterizados como principal função 
comprometida em pacientes graves e com possibilidade de evolução para óbito. Além disso, conforme Meng J, et al. (2020), pacientes com doenças cardiovasculares, incluindo hipertensão, têm mais probabilidade de desenvolver casos graves.

Para Rogers CJ, et al. (2020) a doença de coronavírus 2019 (Covid-19) está tipicamente associada a febre e sintomas respiratórios. Geralmente progride para distúrbios respiratórios graves e falência de múltiplos órgãos, com alta taxa de mortalidade. Pacientes mais velhos ou com comorbidades médicas correm maior risco de doença grave. Inflamação, edema pulmonar e uma resposta imune super-reativa podem levar à hipóxia, desconforto respiratório e danos nos pulmões. As células estromais / células-tronco mesenquimais (CTMs) possuem atividades imunomoduladoras potentes e abrangentes.

Vários estudos in vivo em modelos animais e modelos de pulmão humano vivo demonstraram a impressionante capacidade do MSC de inibir danos nos pulmões, reduzir a inflamação, atenuar as respostas imunes e ajudar na depuração do líquido alveolar. Além disso, Rogers CJ, et al. (2020) descrevem que as CTMs produzem moléculas antimicrobianas e reduzem a dor. Após a administração por via intravenosa, as células viajam diretamente para os pulmões, onde a maioria é sequestrada, um grande benefício para 0 tratamento de doenças pulmonares. Recentemente, a aplicação de CTMs no contexto da doença Covid-19 em andamento e outras doenças respiratórias virais demonstrou redução da mortalidade dos pacientes e, em alguns casos, melhora da função pulmonar a longo prazo.

Células-tronco derivadas de adiposo (ASC), um tipo abundante de CTM, são propostas como uma opção terapêutica para o tratamento de Covid-19, a fim de reduzir a morbimortalidade. Além disso, quando comprovadamente seguro e eficaz, os tratamentos ASC podem reduzir a demanda por recursos hospitalares críticos. O surto em curso do Covid-19 resultou em significativos ônus para a saúde e socioeconômicos em todo o mundo. Existe uma necessidade desesperada de tratamentos seguros e eficazes. As terapias com base celular são uma grande promessa para o tratamento do Covid-19 (ROGERS CJ, et al., 2020).

O gene ECA2 está presente nas células epiteliais dos rins, intestinos, vasos sanguíneos e pulmão (SOUTH AM, et al. 2020). Para Huang J, et al. (2020), os vírus da família coronavírus possuem uma proteína denominada proteína $S$, responsável pela comunicação com as células do agente hospedeiro, como é o caso da célula epitelial pulmonar. Essas células possuem uma alta expressão da ECA2 e reconhecem a proteína $S$ do vírus, permitindo o início da infecção. Ao se ligar a célula, o vírus replica poliproteínas utilizando ribossomos das células hospedeiras, podendo a replicação entre outros processos ocorrerem nas células epiteliais.

O receptor ECA2 responsável pela regulação da pressão arterial dentro do Sistema ReninaAngiotensina. Um relatório feito por Wu Z e McGoogan JM (2020) baseado em 72.314 casos do Centro Chinês de Controle e Prevenção de Doenças indicou que pacientes portadores de doenças crônicas como diabetes e hipertensão estão mais suscetíveis a infecção, possivelmente causado pelo aumento da expressão do ACE2 através do upregulation, um aumento causado por um mecanismo compensatório devido ao uso de medicamentos inibidores da enzima conversora de angiotensina (iECA) e dos bloqueadores dos receptores de angiotensina (BRA) para tratamento da hipertensão arterial e diabetes.

De acordo com Yao XH, et al. (2020), pode-se observar que o SARS-CoV2 adentra no corpo através do trato respiratório através dos cílios apicais, faz ligação com o receptor ACE2 presente nos pulmões, se replica no epitélio da mucosa do trato respiratório e nas células epiteliais alveolares por meio dos microvilos, tendo como consequência a danificação do epitélio da mucosa brônquica e as células epiteliais alveolares. Entretanto, é importante pontuar que as respostas imunológicas do hospedeiro contra o SARS-CoV2 podem também contribuir consideravelmente para a patogênese do Covid-19.

Segundo Chen J, et al. (2020), tanto a idade avançada, quanto a menor contagem de células T CD4 e indicadores de imunossupressão são fatores significantes associados à admissão na UTI. Para Qin C, et al. (2020), a maioria dos casos que apresentam maior gravidade demonstraram níveis elevados de biomarcadores. Junqueira LC e Carneiro J (2004) afirmam que o tecido epitelial está localizado sobre o tecido conjuntivo, cobre e protege superfícies do corpo como no trato respiratório, digestório, urogenital, cavidades corporais, vasos sanguíneos e linfáticos. 
As células apresentam continuidade em sua disposição, apresentam várias faces, tem bastante citoplasma e citoesqueleto desenvolvido. A região da célula voltada para a superfície do lúmen é o polo apical, que apresenta canais iônicos e proteínas responsáveis pelo transporte (GARTNER LP e HIATT JL, 2003).

Dentre algumas especializações do tecido epitelial existe a presença dos microvilos, que são evaginações na superfície apical das células com a finalidade de aumentar a superfície de absorção, presentes principalmente em células absortivas, mas também nas células epiteliais alveolares. Os cílios são outro tipo de especialização do tecido epitelial, possuem movimento e tem a função de transportar materiais nas superfícies das células, como na traqueia (HAM AW e CORMARK DH, 1991)

O exame histológico de um estudo feito por Yao XH, et al. (2020) evidenciou através de análises que são diversas as lesões pulmonares, incluindo inflamação exsudativa alveolar e intersticial com danos em diferentes graus, fibrose, degeneração tecidual, congestão e dilatação de capilares da parede alveolar, além de hemorragia focal. Fox SE, et al. (2020) confirmam em seu estudo que há comumente dano alveolar difuso bilateral com infiltrados exsudativos compostos por células T CD4, Linfócitos T CD8 e macrófagos localizados predominantemente nos espaços intersticiais e em torno de bronquíolos. Os Linfócitos T CD4 puderam ser vistos ainda em grupos ao redor de pequenos vasos contendo pequenos trombos e plaquetas.

\section{Ação da resposta imunológica}

Em uma infecção por agentes contaminantes como o SARS CoV2, nosso corpo utiliza elementos cruciais para tentativa de defesa do organismo, conseguindo diferenciar as células essenciais para o funcionamento do nosso corpo das exógenas com potencial infeccioso. O sistema imunológico é classificado em sistema imune inato e sistema imune adaptativo, é responsável por proteger o corpo através de respostas contra as ameaças ao nosso organismo utilizando mecanismos de barreira em tecidos e órgãos com o auxílio de componentes como células e moléculas solúveis capazes de reconhecer, combater e gerar uma resposta especifica para neutralizar o patógeno, que poderá ser reconhecido com mais agilidade da próxima vez que entrar em contato novamente. Com o sistema imunológico enfraquecido ou com a exposição a grandes quantidades de partículas infecciosas, o organismo pode sentir dificuldade para contenção da infecção e os danos sofridos pelos agentes invasores podem resultar em danos temporários, definitivos e até mesmo em morte (MACHADO PRL, et al., 2004).

O sistema imune inato é composto por macrófagos, neutrófilos, células Natural Killer (NK) e células dendrídicas, está em busca constante por Padrões Moleculares Associados a Patógenos (PAMPs) - lipopolissacarídeos, resíduos de manose e ácidos teicoicos - que ao serem encontrados, são um sinal de invasão que precisa ser combatida. O reconhecimento é feito através de receptores da espécie Toll-like, presente nas membranas celulares e no interior dos macrófagos, neutrófilos e células dendrídicas. Ao haver invasão, as células liberam interferons tipo I (IFN- $\alpha$ e IFN- $\beta$ ) que recrutam as células do sistema inato para reconhecimento e contenção da infecção. O Sistema Complemento é um mecanismo que recruta leucócitos e proteínas plasmáticas em uma tentativa de conter a infecção, realizando uma série de medidas para contenção do vírus, dentre elas o surgimento de sinais inflamatórios como edema, calor, rubor, dor e perda da função nos tecidos e órgãos afetados, além de deposição de fibrina por meio da ativação de diversos elementos (CRUVINEL WM, et al., 2010).

Os invasores capturados são processados no interior dessas células e levados ao complexo principal de histocompatibilidade (MHC), fazendo uma ligação com o sistema imune adaptativo na apresentação desses invasores. A principal característica do sistema imune adaptativo é a memória capaz de reconhecer a invasão novamente em um outro momento e a sua especificidade, tendo como principais componentes celulares os linfócitos B, T CD4 e T CD8, que identificam, neutralizam e destroem os invasores.

Os linfócitos T CD8 com auxílio do MHC tem o papel de reconhecer neutralizar o vírus enquanto os linfócitos T CD4 ajudam os linfócitos B na formação de anticorpos, que depois de criados, agem como uma vacina, sendo capazes de se ligar ao vírus e impedir sua replicação (CRUVINEL WM, et al., 2010). Para Lima JCR, et al. (2012), as imunoglobulinas são anticorpos que comumente são verificadas para observar a presença de infecção ou imunidade já adquirida após contato determinado vírus. 
Um exemplo é a imunoglobulina $M$ (IgM) que indica presença de infecção ativa, já a imunoglobulina $G$ ( $\lg G)$ indica imunidade, afirmando um contato prévio com agente infeccioso em determinado momento independente da presença de sintomas. Atualmente, há uma busca constante por testes rápidos que estão sendo disponibilizados em farmácias e instituições que fazem a mensuração da IgG e a IgM, permitindo que a pessoa testada tenha ciência de que está pu não infectada e precisa se isolar para não facilitar o contágio para outras pessoas ou se ela já teve contato com a infecção em algum momento mesmo sem sintomas, significando que os mecanismos de defesa foram competentes em impedir o desenvolvimento do patógeno. (LIMA JRC, et al., 2012).

\section{Tratamento}

Por ser uma doença nova, não existia tratamento específico para sua cura. Com isso, o tratamento da Covid-19 passou por 2 fases, sendo a primeira com tratamento medicamentoso e a segunda com o uso da vacina. Inicialmente a fase de tentativa de tratamento do Covid-19 foi medicamentosa onde diversos estudos administraram medicamentos variados com o objetivo de tratamento e criação de protocolos clínicos (BARLOW A, et al., 2020).

A identificação urgente de possíveis estratégias de tratamento da infecção por SARS-CoV-2 tornou-se uma prioridade, embora, no início, não existisse um consenso sobre o melhor tratamento farmacológico para pacientes com Covid-19 (BARLOW A, et al., 2020). Diversas pesquisas foram realizadas para encontrar caminhos alternativos no tratamento do Covid-19, de modo que o controle da doença fosse efetivamente alcançado. $O$ teste de substâncias ativas já aprovadas para outras doenças se enquadraram em uma das formas de caminhos alternativos para o tratamento (OLIVEIRA A e SILVEIRA D, 2020).

Alguns medicamentos que foram aprovados e experimentados em pacientes com SARS-CoV e MERS começaram a ser avaliados para o tratamento de Covid-19, que já apresentava como vantagem uma base de conhecimentos em relação ao uso e segurança em seres humanos. Dentre os medicamentos mais utilizados estavam: Cloroquina, Hidroxocloroquina, Remdesivir, Baricitinibe, o anticorpo monoclonal receptor da interleucina-6 (IL-6) Tocilizumab e os medicamentos anti-influenza Favipiravir e Umifenovir, como pode ser observado no Quadro 1 (TRIGGLE CR, et al., 2020).

Quadro 1 - Principais medicamentos em estudo para o combate da Covid-19

\begin{tabular}{|c|c|c|}
\hline $\begin{array}{l}\text { Ordem de } \\
\text { preferência de } \\
\text { uso }\end{array}$ & Seu real uso & Benefícios com o uso associados a Covid-19 \\
\hline Cloroquina & $\begin{array}{l}\text { Usada pela primeira vez para tratar a } \\
\text { malária, mas tem sido usada com } \\
\text { sucesso contra doenças auto-imunes, } \\
\text { como artrite reumatóide e lúpus }\end{array}$ & $\begin{array}{l}\text { Pode interferir na glicosilação do receptor da } \\
\text { membrana celular para o coronavírus, ACE2 } \\
\text { impedindo a ligação e a entrada celular do vírus }\end{array}$ \\
\hline Hidroxicloroquina & $\begin{array}{l}\text { Eficaz contra malária, lúpus e artrite } \\
\text { reumatóide }\end{array}$ & $\begin{array}{l}\text { Em doses maiores que as apropriadas à } \\
\text { cloroquina podem ser usadas para fins antivirais }\end{array}$ \\
\hline Baricitinibe & $\begin{array}{l}\text { Aprovado para o tratamento de artrite } \\
\text { reumatóide }\end{array}$ & $\begin{array}{l}\text { Deve interromper a entrada da endocitose SARS } \\
\text { CoV-2 mediada por ACE2 nas células }\end{array}$ \\
\hline Remdesivir & $\begin{array}{l}\text { Desenvolvido para tratar infecções } \\
\text { causadas pelo vírus Ebola }\end{array}$ & $\begin{array}{l}\text { Seu metabolito ativo é um análogo de } \\
\text { nucleosídeo de adenosina que inibe a ação da } \\
\text { RNA polimerase viral, impedindo a replicação } \\
\text { viral }\end{array}$ \\
\hline $\begin{array}{l}\text { Ritonavir e } \\
\text { Lopinavir }\end{array}$ & $\begin{array}{l}\text { É destinado, em combinação com } \\
\text { outros agentes antirretrovirais, ao } \\
\text { tratamento de infecção por HIV }\end{array}$ & $\begin{array}{l}\text { Por serem inibidores da protease, impedem a } \\
\text { replicação viral em virtude do bloqueio da } \\
\text { clivagem proteolítica das proteínas precursoras } \\
\text { exiqidas pelo vírus }\end{array}$ \\
\hline Favipiravir & $\begin{array}{l}\text { Medicamento anti-influenza, } \\
\text { desenvolvido e aprovado para o } \\
\text { tratamento da gripe }\end{array}$ & $\begin{array}{l}\text { Inibe a polimerase viral dependente de RNA viral } \\
\text { demonstrou boa eficácia clínica contra o Covid } \\
19 .\end{array}$ \\
\hline Ivermectina & Droga antiparasitária & In Vitro sugerem benefícios potenciais. \\
\hline Camostat & $\begin{array}{l}\text { Medicamento aprovado para } \\
\text { pancreatite e esofagite de refluxo }\end{array}$ & $\begin{array}{l}\text { Tem como alvo a protease serina-treonina } \\
\text { (TMPRSS2), que é a protease utilizada pelo } \\
\text { SARS-CoV-2 para preparar a proteína spike } \\
\text { facilitar a ligação à ECA2 e a entrada na célula. }\end{array}$ \\
\hline
\end{tabular}

Fonte: Silva CS, et al., 2021. Baseado em Triggle CR, et al., 2020. 
A busca por drogas capazes de reverter a forma grave da doença, aliada a busca por uma vacina que impedisse a infecção pelo SARS-CoV-2, ainda não evitavam sua propagação, contudo, uma medida de combate à Covid-19 que foi comprovadamente eficaz contra a disseminação do vírus e contribuição para a diminuição de novos casos, foi a aplicabilidade da realização de quarentena juntamente com o distanciamento social, higienização das mãos e uso máscaras e álcool gel (LIMA-COSTA MF, et al., 2020).

Logo após os experimentos com as medicações e seus variados protocolos, iniciou-se a produção das vacinas mundialmente. Segundo a OMS, existiam 70 vacinas em desenvolvimento. E, qualquer candidato a vacina teria que direcionar os recursos presentes nos dois tipos de vírus: $S$ e $L$ identificados por pesquisadores de Pequim em pacientes infectados, para ser eficaz (LOCKEY C, et al., 2020). Esforços e ensaios clínicos de fase 1 para desenvolvimento de novas vacinas, estavam em andamento no Reino Unido, Estados Unidos, Alemanha, França e China.

Mas, é no Reino Unido, na Universidade de Oxford, que iniciaram um teste em humanos e animais da vacina ChAdOxl e espera-se que esteja disponível até o final de 2020 (TRIGGLE CR, 2020). Em julho de 2020, havia, no mundo, 23 vacinas sendo testadas em seres humanos. No entanto, apenas duas encontravam-se na Terceira e última etapa dessa testagem, com uma totalidade de 140 candidatas em fases anteriores de desenvolvimento (WHO, 2020). Vale salientar que, no mesmo período, o Brasil estava envolvido no desenvolvimento clínico das duas. Associado à empresa chinesa Chinovac, encontrava-se o Instituto Butantã e, a Fiocruz/Biomanguinhos, com à AstraZeneca (GUIMARÃES R, 2020).

Castro REV (2020) divulgou em novembro de 2020 que, numa análise final dos dados de fase 3 da vacina candidata BNT162b2, baseada no RNA mensageiro (mRNA), apresentou 95\% de eficácia contra a Covid-19, onde foi consistente em dados demográficos como idade, sexo, raça e etnia. Por fim, a eficácia foi observada também em adultos com mais de 65 anos de idade num percentual de $94 \%$. Nos dias atuais, encontra-se a segunda do tratamento contra a doença, onde vacinas foram desenvolvidas e, recentemente aprovadas pela ANVISA, onde seu uso está sendo disseminado em todo o mundo.

\section{CONSIDERAÇÕES FINAIS}

A Covid-19 é uma doença viral, de elevada transmissibilidade, que se beneficia da fragilidade imunológica para se desenvolver no organismo, utilizando uma série de medidas para contenção e eliminação do vírus, desde barreiras físicas a até defesas celulares. Embora o tratamento ainda não seja completamente conhecido, testes com fármacos alternativos estão sendo realizados constantemente. Suas ações estão sendo monitoradas para compreensão dos mecanismos mais efetivos na luta contra a infecção e, as vacinas, após muito estudo e testagem, foram liberadas recentemente para uso, em busca do tratamento e cura da Covid-19. Diante do contexto geral, ainda se fazendo necessário o isolamento social, distanciamento, uso de máscaras e álcool gel na luta contra esse vírus, bem como a continuidade dos estudos sobra a Covid-19.

\section{REFERÊNCIAS}

1. BARLOW A, et al. Review of Emerging Pharmacotherapy for the Treatment of Coronavirus Disease 2019. Pharmacotherapy, 2020: 416-437.

2. BRITISH BROADCASTING CORPORATION (BBC NEWS). Covid-19: o mapa que mostra o alcance mundial da doença. Disponível em: https://www.bbc.com/portuguese/internacional-51718755. Acessado em 25 de janeiro de 2020.

3. CASTRO REV. Vacina contra Covid-19 apresentou 95\% de eficácia em estudo de fase 3. Disponível em: https://pebmed.com.br/vacina-contra-a-covid-19-apresentou-95-de-eficacia-em-estudo-de-fase-3/. Acessado em 20 de janeiro de 2020.

4. CHEN J, et al. Clinical progression of patients with COVID-19 in Shanghai, China. J Infect, 2020; 80(5): e1-e6.

5. CRUVINEL WM, et al. Sistema imunitário - Parte I. Fundamentos da imunidade inata com ênfase nos mecanismos moleculares e celulares da resposta inflamatória. Rev Bras Reumatol, 2010; 50(4): 434-447.

6. DUARTE-NETONA.Pulmonary and systemic involvement of COVID-19 assessed by ultrasound-guided minimally invasive autopsy. Histopathology, 2020; 77(2): 186-197.

7. FEHR AR, PERLMAN S. Coronaviruses: an overview of their replication and pathogenesis. Methods Mol Biol, 2015; 1282:1-23. 
8. FOX S, et al. Pulmonary and Cardiac Pathology in Covid-19: The First Autopsy Series from New Orleans. MedRxiv.

9. GARCIA LP, DUARTE E. Intervenções não farmacológicas para o enfrentamento à epidemia da COVID-19 no Brasil. Epidemiologia e Serviços de Saúde, 2020; 29(2): 2-4.

10. GARTNER LP, HIATT JL. Tratado de Histologia em Cores. 2 ed. Rio de Janeiro. Guanabara Koogan, 2003.

11. GORBALENYA AE, et al. Severe acute respiratory syndrome-related coronavirus: the species and its viruses-a statement of the Coronavirus Study Group. Nature Microbiology, 2020.

12. GUIMARÃES R. Vacinas Anticovid: um Olhar da Saúde Coletiva. Ciênc. saúde coletiva 25(9): 3579-3585, 2020.

13. HAM A.W., CORMACK D.H. Histologia. 9 ed. Rio de Janeiro: Guanabara Koogan,1991. p. 106, 147, 179

14. HUANG J, et al. Pharmacological Therapeutics Targeting RNA-Dependent RNA Polymerase, Proteinase and Spike Protein: From Mechanistic Studies to Clinical Trials for COVID-19. J Clin Med, 2020; 9(4): 1131.

15. JUNQUEIRA LC, CARNEIRO J. Histologia Básica. 10 ed. Rio de Janeiro: Guanabara Koogan, $2004 ; 66$ p.

16. KOWALSKI LP, et al. COVID-19 pandemic: effects and evidence-based recommendations for otolaryngology and head and neck surgery practice. Head Neck Actions, 2020.

17. LI YC, et al. The neuroinvasive potential of SARS-CoV2 may play a role in the respiratory failure of COVID19 patients. J Med Virol, 2020; 92(6): 552-555.

18. LIMA JRC, et al. Interpretação da presença dos anticorpos lgM e lgG nos testes rápidos para dengue: análise da prevalência dos anticorpos da dengue em Fortaleza, no vigésimo ano da epidemia. Rev. Soc Bras Med Trop [online], 2012; 45(2): 163-167.

19. LIMA-COSTA MF, et al. Distanciamento social, uso de máscaras e higienização das mãos entre participantes do Estudo Longitudinal da Saúde dos Idosos Brasileiros: iniciativa ELSI-COVID-19. Cadernos de Saúde Pública, 2020; 36(15): 3.

20. LOCKEY C, et al. The Extracellular Domain of Two-component System Sensor Kinase VanS from Streptomyces coelicolor Binds Vancomycin at a Newly Identified Binding Site. Scientific Reports, 2020; 10(5727).

21. LU W, et al. Psychological status of medical workforce during the COVID-19 pandemic: A cross-sectional study. Psychiatry Research, 2020; 288.

22. MACHADO PRL, et. al. Immune response mechanisms to infections. An Bras Dermatol [online], 2004; 79(6): 647662.

23. MENG J, et al. Renin-angiotensin system inhibitors improve the clinical outcomes of COVID-19 patients with hypertension. Emerg Microbes Infect, 2020; 9: 758-760.

24. MINISTÉRIO DA SAÚDE. Boletim epidemiológico Doença pelo novo coronavírus (COVID-19). Disponível em: https://www.saude.gov.br/noticias/agencia-saude. Acessado em: 16 de abril de 2020.

25. PIMENTEL RMM, et al. The dissemination of COVID-19: an expectant and preventive role in global health. J Hum Growth Dev, 2020; 30(1): 135-140.

26. QIN C, et al. Dysregulation of immune response in patients with COVID-19 in Wuhan, China. Clin Infect Dis, 2020; 248: 4-11.

27. ROGERS CJ, et al. Rationale for the clinical use of adipose-derived mesenchymal stem cells for COVID-19 patients. J Transl Med, 2020;18(1): 203.

28. SOUTH AM, et al. COVID-19, ACE2, and the cardiovascular consequences. Sou J Physiol Coração Circ Physiol, 2020, 318(5): H1084-H1090.

29. TRIGGLE CR, et al. COVID-19: Learning from Lessons to guide treatment and prevention interventions. mSphere, 2020; 5(3): e00317-20.

30. WORLD HEALTH ORGANIZATION (WHO). Severe acute respiratory syndrome (SARS). Disponível em: https://www.who.int/csr/sars/en/ Acessado em 03 de fevereiro de 2020.

31. WORLD HEALTH ORGANIZATION (WHO). Draft landscapeof COVID-19 candidate vacines.21 July 2020. Geneva: WHO. Disponível em: https://www.who.int/publications/m/item/draftlandscape-of-covid-19-candidate-vaccines. Acessado em 20 de janeiro de 2020.

32. WORLD HEALTH ORGANIZATION (WHO). 2020. In: Update 95 - SARS: Chronology of a serial killer. WHO; 2003. Disponível em: https://www.who.int/csr/don/archive/year/2003/en/. Acessado em 22 junho de 2020.

33. WU JH, et al. Pathological changes of fatal coronavirus disease 2019 (COVID-19) in the lungs: report of 10 cases by postmortem needle autopsy. 2020;49(6): 568-575.

34. WU Z, MCGOOGAN JM. Characteristics of and Important Lessons from the Coronavirus Disease 2019 (COVID-19) Outbreak in China: Summary of a Report of 72314 Cases from the Chinese Center for Disease Control and Prevention. JAMA, 2020.

35. WU Z, MCGOOGAN JM. Characteristics of and Important Lessons from the Coronavirus Disease 2019 (COVID19) Outbreak in China: Summary of a Report of 72314 cases from the Chinese Center for Disease Control and Prevention. JAMA, 2020.

36. YAO XH, et al. A Pathological Report of Three COVID-19 Cases by Minimal Invasive Autopsies. Zhonghua Bing Li Xue Za Zhi, 2020; 49(5): 411-417. 